\title{
LA LEYENDA ARTÚRICA EN LA PENÍNSULA IBÉRICA: UNA REFLEXIÓN
}

Antonio Contreras Martín

IEM

tcontreras@telefonica.net

Al estudiar la leyenda artúrica en la Península Ibérica, tanto desde sus manifestaciones literarias como plásticas, debe considerarse que es necesario, por un lado, realizar su análisis a partir del principio de 'transversalidad', puesto que ello resulta imprescindible para tratar de comprender cómo pudieron ser entendidas por sus receptores (pues, como es sabido, una obra logra su plenitud semántica en su contexto y es susceptible de reinterpretarse en otros); y por el otro, hay que tener en cuenta, en el caso de las obras literarias, la importancia que la narrativa artúrica y caballeresca tuvo en la renovación de los ideales sobre los que deberían regirse los estados autoritarios europeos: una forma de plasmar el ideal caballeresco que configuró la idea de Europa desde finales del siglo XIv, al ofrecer un modelo, una serie de propuestas a los interrogantes que se les plantearon a los hombres y mujeres desde la Baja Edad Media hasta el primer tercio del siglo xvI.

$\mathrm{El}$ análisis de las obras plásticas ha puesto de manifiesto dos aspectos básicos. Por un lado, la temprana recepción de la Materia de Bretańa ya en el primer cuarto del siglo XII, según demuestra la columna historiada que narra el viaje de Tristán herido a Irlanda, procedente de la destruida puerta norte (Porta Francígena) de la Catedral de Santiago de Compostela, explicable mediante la transmisión oral de la leyenda a lo largo del Camino de Santiago. Esto se documenta también por medio de los testimonios onomásticos, como el de Martin Galván (II36); y lo mismo es aplicable a la amplia difusión y alcance de la Materia, ya que en el reino de Granada, en el tercer cuarto del siglo XIV y a instancias de Muhammad v, se representó el episodio del Puente de la Espada del Lancelot en prose (hacia I215-I225) en la Sala de la Justicia de La Alhambra. Y, por el otro, la pronta asimilación y reinterpretación de la Materia ya en el primer tercio del siglo XIII, evidenciadas, por ejemplo, en Alfonso IX de León, quien se 'representó' a imagen de Yvaín, el protagonista del Chevalier au Lion de Chrétien de Troyes, como revela la representación escultórica en el tímpano de la portada occidental de la antigua iglesia del monasterio de Santa María de Penamayor (Lugo). 
Por lo que respecta a las obras literarias, pertenecientes a los tres grandes ciclos (Vulgata, Post-Vulgata y Tristán en prosa) que han pervivido de forma fragmentaria o extensa en catalán, castellano y gallego-portugués, se observa una triple orientación. En primer lugar, la edición solvente de textos, como las ya publicadas (A Demanda do Santo Graal, Lanzarote del Lago, Tristán de Leonis, y los fragmentos del Códice de Tristán y de Livro do Tristan) o las que están en proceso de edición (El Baladro del Sabio Merlín, Demanda del Santo Grial y La Questa del Sant Grasal), con las que se posibilita un más amplio acercamiento y se facilita su estudio. En segundo lugar, el análisis global o parcial de las obras, entre los que resultan paradigmáticos los del Lanzarote del Lago, donde se aúnan al final de la obra ('folios originales') episodios o motivos de los tres grandes ciclos, los del Tristán de Leonís y los del Códice de Tristán, que son especialmente interesantes en lo relativo a las posibles fuentes y variantes, para tratar de establecer filiaciones, correspondencias o innovaciones con respecto de las fuentes (cuando se cuenta con ellas), o en relación con otros textos del mismo o de otro ciclo, con el fin de interpretarlos. Y, en tercer lugar, la investigación de inventarios de archivos y bibliotecas coetáneos que informan de las obras más difundidas y de las tendencias del momento, como por ejemplo la del marqués de Santillana, la de la reina Isabel la Católica o las de los mercaderes (burgueses) catalanes y valencianos.

En lo referente a los estudios que se han ocupado del análisis e interpretación de obras literarias, es posible distinguir diversas tendencias:

a) Los estudios centrados en aspectos formales o estructurales, realizados desde la perspectiva de la teoría literaria y del 'arte de la novela' (la terminología literaria, las fórmulas y expresiones formularias, la técnica del entrelazamiento, la combinación de motivos, los 'encuentros especulares', la focalización, la modalidad y la cronología) han permitido conocer mejor no sólo aspectos intra o intertextuales, incardinando así las obras en la tradición literaria receptora y fijando su influencia en creaciones posteriores (textos caballerescos, v. gr. Libro del Caballero Zifar o Amadis de Gaula, y libros de caballerías, v. gr. Palmerín de Ingalaterra o Espejo de Príncipes y Caballeros), sino también observar cómo trabajaron los traductores, adaptadores o compiladores e incluso los copistas.

b) Los análisis que se han ocupado del armamento y de la heráldica, en lo tocante tanto a su terminología como a su simbolismo (v. gr. la espada de Lanzarote - Lanzarote del Lago y El Baladro del Sabio Merlin-, la Lanza Vengadora de Baalaín -Demanda del Santo Grial y A Demanda do Santo Graal-, el yelmo de Arturo -Demanda del Santo Grial y A Demanda do Santo Graal-, el escudo de Mordraín —Demanda del Santo Grial y A Demanda do Santo Grial-, la espada y el escudo de Tristán — Tristán de Leonis — o las espadas de Galaz — La Questa del Sant Grasal-) han contribuido, por un lado, a fijar la semántica del vocabu- 
lario caballeresco; y, por el otro, a rastrear el proceso de ósmosis, atestiguado en la heráldica, entre la realidad y la ficción, representado ejemplarmente por el rey Alfonso IX de León y los paralelismos entre su escudo y el de Yvaín (Lanzarote del Lago).

c) Asimismo, el análisis de la toponimia literaria ha permitido reconstruir y trazar el mapa de la geografía artúrica y, de ese modo, establecer la relación existente entre la tradición y la originalidad.

d) Los estudios que se han centrado en la reconstrucción total o parcial de las 'biografías' artúricas han posibilitado un mejor conocimiento de los modelos masculinos, interpretables como formas de comprensión del imaginario caballeresco (como, por ejemplo, Arturo, Lanzarote, Yvaín, Galván o Galaz), y femeninos, identificables como modos de comportamiento 'eclesiástico' (como, por ejemplo, la Hermana de Perceval), o 'cortés,' en el que destacan los ejemplos de las reinas Ginebra e Iseo, cuya esterilidad se ha podido aclarar al recurrir a la tratadística médica, y se explicaría como consecuencia de su comportamiento 'lujurioso', que les impediría concebir descendencia.

e) De igual modo, las investigaciones sobre los lugares de entierro y los ritos funerarios han puesto de manifiesto su adecuación a los usos y costumbres coetáneos, no sólo en el ámbito artístico (v. gr. la tumba del rey Lot y las de los doce reyes, en El Baladro del Sabio Merlín; las de Tristán e Iseo, en Tristán de Leonís; las de los hermanos de Galván, en Demanda del Santo Grial y A Demanda do Santo Graal; y la de la Galaz, en Demanda del Santo Grial), sino también en el jurídico, en el ideológico y en el religioso, de entre los que sobresalen los casos de Tristán (Tristán de Leoniśs) y, sobre todo, el de Galaz, pues ofrece un originalísimo y único caso relacionado con la tradición del 'Lagar Místico' (Demanda del Santo Grial). Tales investigaciones han permitido aclarar el valor simbólico de esos usos o ritos, al igual que sucede con la caza, en cuanto actividad indesligable de la condición nobiliaria o regia (v. gr. los episodios de Arturo y la caza del jabalí en Lanzarote del Lago, o el de Galván y la caza del ciervo blanco en El Baladro del Sabio Merlín).

f) Los estudios que han tenido por objeto analizar los sueños y las visiones (v. gr. el sueño de Erec, las visiones del ciervo blanco y de los leones, el sueño de Galaz en el Castillo Felón o la visión de Helaín el Blanco en A Demanda del Santo Graal), algunos de los episodios más relevantes (v. gr. los episodios de la 'Carreta' y del 'Ajedrez Mágico' del Lanzarote del Lago, en la Castilla bajomedieval y en la de Isabel la Católica, respectivamente) y las anotaciones marginales (v. gr. las de un lector del siglo Xvi en Lanzarote del Lago) han contribuido a aclarar sus significados e incluso reestablecerlos en distintos momentos de recepción.

g) Por último, habría que señalar las investigaciones que se han interesado por la 'memoria artúrica' con el fin de reconstruirla a partir de algunos de sus 
elementos configuradores, como son el 'libro', plasmación de los hechos artúricos y garantía de salvaguarda y recuerdo de los mismos (v. gr. Libro de las Aventuras en Tristán de Leonis); las 'tumbas' (v. gr. la tumba de Erec, en Demanda del Santo Grial y A Demanda do Santo Graal), las 'armas' (v. gr. el yelmo de Arturo, en Demanda del Santo Grial y A Demanda do Santo Graal) y el 'cabello' (v. gr. los cabellos del Lanzarote y de Ginebra, en Lanzarote del Lago), lugares y objetos de identificación y recuerdo.

No quisiera concluir esta reflexión sin referirme a la próxima aparición del proyecto The Arthur of the Iberian (dir. David Hook) en la serie "Arthurian Literature in the Middle Ages", Cardiff, University of Wales Press (en prensa), obra a cargo de un grupo internacional de investigadores, entre los que me hallo, en la que se ofrecerá una visión de conjunto sobre la leyenda artúrica en la Península Ibérica. 